\title{
Radial Artery of the Endometrium
}

National Cancer Institute

\section{Source}

National Cancer Institute. Radial Artery of the Endometrium. NCI Thesaurus. Code C34013.

Arteries that arises from the arcuate arteries in the myometrium and supply small straight arteries to the basal layer of the endometrium and spiral arteries to the functional zone of the endometrium. 